\title{
Nature of the Features of Kimberlite Placement
}

\author{
Vladimir Shkodzinsky \\ Diamond and Precious Metals Geology Institute of Siberian Branch of the Russian Academy of Sciences (IGABM SB RAS), Yakutsk, \\ Russia
}

\author{
Email address: \\ Shkodzinskiy@diamond.ysn.ru
}

\section{To cite this article:}

Vladimir Shkodzinsky. Nature of the Features of Kimberlite Placement. Earth Sciences. Vol. 10, No. 4, 2021, pp. 157-164. doi: $10.11648 /$ j.earth.20211004.12

Received: July 16, 2021; Accepted: July 26, 2021; Published: August 18, 2021

\begin{abstract}
The obtained evidence of hot heterogeneous accretion of the Earth leads to a fundamentally new solution to genetic problems. According to these data, the kimberlites were formed as a result of the rise of the last residual melts of the bottom peridotite layer of the magmatic ocean, which arose as a result of impact heat release during accretion. The diamond crystallized due to the accumulation of carbon in the residual melts during fractionation. The absence of kimberlites in oceanic and collision regions is due to the expansion of the fractionation products of the magmatic ocean by surfaced mantle plumes during the formation of these regions. The all-earth distribution of the magmatic ocean explains the presence of kimberlites on all the studied ancient platforms. A very high degree of crystallization of the peridotite layer is the reason for the small volume of kimberlite residual melts and the bodies formed by them. The low temperature of kimberlite magmas caused their decompression solidification after boiling at the shallow stage of ascent and explosion under the influence of the high pressure of the fluid phase preserved by solidification. This is the reason for the formation of kimberlite pipes and the absence of kimberlite lavas.
\end{abstract}

Keywords: Kimberlites, Diamond, Magmatic Ocean, Decompression Solidification

\section{Introduction}

Finding out the patterns of kimberlite placement and their nature is of fundamental importance for the successful prediction and search for diamond deposits. To do this, it is important to know the origin of diamonds, kimberlites and geospheres. However, until recently, these genetic problems did not have a reasonable and convincing solution. As the performed analysis [1] showed, this was due to the fallacy of the hypothesis of cold homogeneous accretion of the Earth used for their solution and not taking into account the existence and fractionation of a global magmatic ocean in a large part of its geological history, which arose as a result of the hot formation of our planet.

This formation is evidenced by calculations that showed the impact heating of its substance during accretion at $34,000^{\circ} \mathrm{C}$ [2], the existence of magmatic fractionation trends in mantle xenoliths and Early Precambrian crystal complexes, the complete correspondence of the isotopic age and crystallization temperature of their various rocks to the sequence of formation during fractionation, the projection of the earliest geothermal gradients to a very high temperature (up to $1000^{\circ} \mathrm{C}$ ) on the Earth's surface. A vivid confirmation of the huge heat release during accretion is the melting and partial evaporation of falling meteorites. The sharp chemical disequilibrium of mantle rocks with metallic iron, the presence of water and carbon dioxide on the Earth, and not the products of their reduction by iron, and other data indicate that silicate and iron particles have never been mixed in the Earth's interior. Consequently, the accretion was hot and heterogeneous. Taking into account this formation of the Earth, all genetic problems of petrology receive a wellgrounded solution in detail [3].

\section{Origin of Geospheres, Kimberlites and Diamonds}

The Earth's core appeared earlier than the silicate mantle due to the adhesion of iron particles under the influence of magnetic forces after cooling the protoplanetary disk to the Curie temperature. With a small body size, these forces were billions of times more powerful than gravitational ones [1]. 
An example of the effectiveness of magnetic forces is the rapid unification of magnetized small iron objects, whereas under the influence of the forces of mutual gravitational attraction, they never unite. The Sun at that time had a thousand times more powerful magnetic field than at present, because it was at the evolutionary stage of Tau Taurus and therefore strongly magnetized iron particles. The disappearance of protoplanetary disks near stars with an age of more than 10 million years [4] indicates that accretion occurred approximately 5-10 million years after the appearance of the Sun.

The silicate particles that fell on the iron core melted under the influence of impact heat release and formed a global magmatic ocean. Its bottom part crystallized and fractionated under the influence of an increase in the pressure load that occurred during the accretion of the upper parts. Residual melts surfaced, and the deposited cumulates formed the ultrabasic substance of the mantle. Due to the still small depth of the magmatic ocean and the reduced force of gravitational attraction on a small Earth, the bottom fractionation of the early magmatic ocean was low-baric. This led to the formation of a large number of acidic and tholeiitic residual melts, which explains the wide distribution of rocks of this composition on Earth and the subsequent appearance of an acidic crust (Figure 1). The increase in the depth and temperature of the magmatic ocean as accretion occurred caused the formation of basic and ultrabasic residual melts, corresponding layers in the magmatic ocean and the reverse geothermal gradient in the mantle.

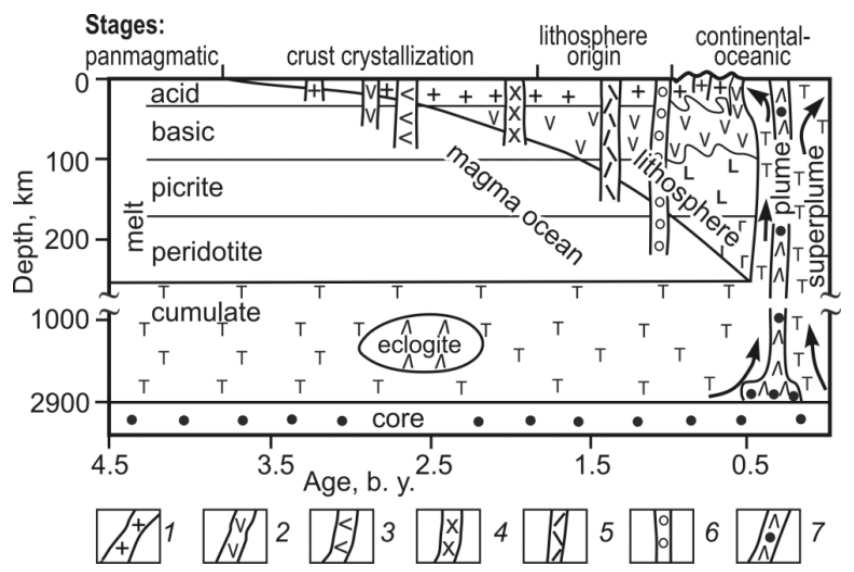

Figure 1. The scheme of formation of various geodynamic environments and magmas: 1 - acidic, 2 - basic, 3 - anorthosite, 4 - alkaline-basic, 5 alkaline-ultrabasic carbonatite-containing, 6 - kimberlite, 7 - oceanic and traps, sometimes containing xenoliths of the core.

The layered structure of the magmatic ocean and a significant increase in its density with depth (from 2.3 to 2.8 $\mathrm{g} / \mathrm{cm}^{3}$ ) caused the absence of convection of melts in it after the completion of accretion and its solidification from top to bottom as a result of mainly conductive heat losses. The long duration of such solidification led to the molten state of the Earth's surface in the first approximately 750 million years of its existence and explains the absence of rocks older than 3.8 billion. years and craters of the giant meteor bombardment that completed the accretion. The subsequent solidification of the acidic layer of the magmatic ocean and its deeper layers led to the emergence of early Precambrian crystalline complexes of the acidic crust and the lithosphere of the ancient platforms, respectively. The surfacing of residual melts from the crystallized various layers of the magmatic ocean caused the evolution of the magmatism of the ancient platforms from acidic to alkaline-basic and then to alkalineultrabasic carbonatite-containing and to kimberlite.

The absence of kimberlites in oceanic regions contradicts the most common assumption about the origin of their magmas as a result of the separation of smelts from mantle plumes. These magmas were formed from residual melts of the bottom peridotite (mainly harzburgite) layer of the magmatic ocean. The top-down crystallization of the magmatic ocean explains the relatively young (236 million years) average age of the kimberlites [1].

Kimberlite melts were formed as a result of two stages of magmatic fractionation. At the early synaccretion stage, the peridotite layer of the magmatic ocean was formed by the initial stages of the bottom compression fractionation of impact magmas with the accumulation of mainly silicic acid in the residual melts. This is the reason for significant (23-45\%) variations in the content of silicic acid in kimberlites. At a late stage, high-pressure fractionation of peridotite magmas occurred with the accumulation of potassium, light rare earths and volatile components in the residual melts. This explains the peculiarities of the composition of kimberlites.

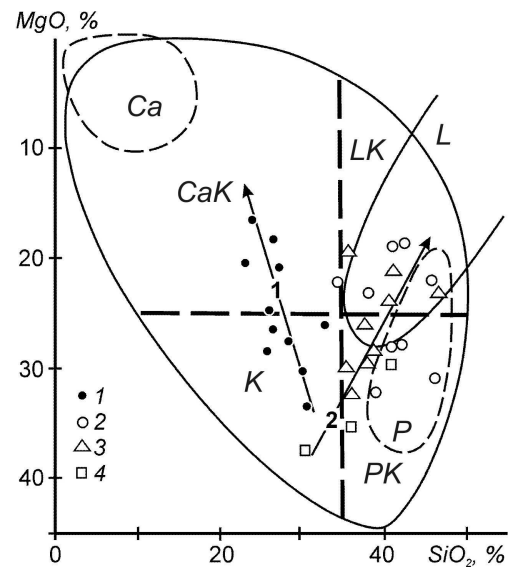

Figure 2. The ratio of $\mathrm{MgO}-\mathrm{SiO}_{2}$ in carbonatites (Ca), kimberlites (K), and lamproites (L). CaK - carbokimberlites, LK - lapmprokimberlites, $P$ picrites, and $P K$ - picrokimberlites. 1-4-points of the average composition of the pipes of Yakutia (1), Arkhangelsk Province (2), Africa (3) and Canada (4). Fractionation trends: 1 - carbonatite, 2 -lamproite.

The last ultrabasic impact melts that emerged were located at the bottom of the magmatic ocean and fractionated little due to the termination of accretion. The most mafic kimberlites were formed from such parts of the bottom layer. This is the reason for the existence of two varieties of kimberlites. In Africa, in addition to the kimberlites themselves, orangites were distinguished [5] containing more potassium and silicic acid. S. V. Belov and co-authors distinguish kimberlite-carbonatite and lamproite-orangite-majgavanite subfamilies. The author of this 
work identified two fractionation trends in kimberlites kimberlite-carbonatite and kimberlite-lamproite [3] (Figure 2). In the first, the content of silicic acid decreases and the amount of carbon dioxide increases with a decrease in the amount of magnesium. Kimberlites of most pipes of Yakutia are placed on this trend. They contain very high diamond contents, among which there is a large proportion of octahedra. In the kimberlitelamproite trend, the content of silicic acid increases with fractionation, the pipes of the Arkhangelsk Province, Africa and Canada belong to it, they are characterized by a small proportion of octahedra among diamonds.

Mantle xenoliths in kimberlites are not remnants of the parent substrate of kimberlite magmas, as is usually assumed, but cumulates of fractionated peridotite magmas during the formation of kimberlite residual melts. This is confirmed by the constant presence of a significant amount of them in kimberlite pipes, the content of diamonds in them sometimes, and the gradual approximation of the composition of the most recent xenolith rocks to kimberlites [3]. The presence in some xenoliths, in contrast to kimberlites, of very high (up to the first percent) diamond contents indicates its participation in the processes of gravitational deposition along with rockforming minerals.

The change in the composition of melts during fractionation led to its reaction with earlier minerals and to their partial replacement in kimberlites and mantle xenoliths with lower-temperature minerals. The presence of such substitutions does not indicate the course of metasomatic processes in the mantle, as is often assumed. An independent fluid phase cannot exist in the mantle, due to the intense melting of rocks in its presence and complete dissolution in the resulting melt.

It was most often assumed that the diamond in kimberlites is xenogenic, captured from the Archean mantle [5]. However, as the generalization of the published data [1] showed, more than $60 \%$ of inclusions in diamonds are postArchean, so this mineral could not be captured from the ancient mantle. The metasomatic formation of diamonds in the mantle and from carbon submerged during subduction of carbonaceous sediments was assumed [6]. But the metasomatic processes cannot occur in the mantle due to the melting of rocks in the presence of a fluid and its complete dissolution in the melt. There are no kimberlites and diamonds in the subduction zones, which contradicts their subduction origin. Evidence of subduction genesis is usually considered to be the light carbon isotopic composition of some diamonds characteristic of the Earth's crust. However, a clear direct correlation of the light carbon content in diamonds with the amount of impurities accumulated in residual melts [3] and a higher content in igneous rocks of light rare earths compared to heavy ones indicate the accumulation of a light carbon isotope in the residual melt during fractionation. This is confirmed by the enrichment of mainly late diamonds - rhombododecahedra, cubes, diamond aggregates.

During the hot accretion of the Earth, diamond was formed in the bottom peridotite layer of the magmatic ocean due to the accumulation of carbon in the residual melt, since this component was almost not part of the crystallized rockforming minerals. A small amount of carbon was initially present in the melt due to the dissociation of carbon-containing compounds. Diamond began to form about 3.5 billion years ago with the still predominantly harzburgite composition of the bottom peridotite layer. This explains the presence of inclusions of this composition in diamonds and their most ancient age. The low content of free carbon in the melts caused a relatively small amount of diamonds (usually the first carats per ton) even in the richest kimberlites. In the case of the sometimes assumed introduction of carbon by fluids or ocean sediments submerging during subduction, the diamond content would be hundreds to thousands of times greater.

In the rising mantle plumes, the substance was melting under the influence of pressure reduction. An increase in the amount of the melt at the same time led to a decrease in the carbon concentration in it. Therefore, diamonds usually did not crystallize in the plumes, although the substance of the plumes was at a very high pressure at the deep stage of ascent. Diamonds could arise only during the processes of crystallization and fractionation of plume magmas during their cooling under high pressure conditions. This is the reason for the occasional presence of diamonds in alkaline basites, lamprophyres, and minettes [7]. However, the duration of crystallization of their magmas under high pressure conditions was incomparably shorter than the duration ( $2-3$ billion years) of crystallization of the peridotite layer of the magmatic ocean, which was ancestral for kimberlites. This explains the hundreds-thousands of times smaller size of diamonds in non-kimberlite rocks (tenths-hundredths of a millimeter).

The very low viscosity of peridotite melts (the first poises) caused a high rate of carbon diffusion in them. Therefore, it managed to reach the ends of the diamond crystal growth layers and joined them, since more free covalent bonds were exposed here than on the faces. As a result, perfect sharpedged diamond octahedra with mirror-smooth faces were formed by layer-by-layer tangential growth. During fractionation, the content of silicon, aluminum and other multivalent elements in the residual melts increased. This led to an increase in their viscosity by thousands of times, to an approximately the same decrease in the rate of carbon diffusion and to an increase in the degree of supersaturation of the melt by it. As a result, new crystallization centers appeared faster, the area of the formed growth layers on the faces decreased, and polycentric, layered, block and roundedstepped octahedra with convex faces were formed. With a further decrease in the area of the formed layers, the edges and vertices were replaced by faces of a rhombododecahedron and a cube, respectively, and crystals of transitional morphology were formed, and then rhombododecahedral and cubic diamonds appeared. The tangential layer-by-layer growth was replaced by a radial one and various sculptures on crystals were formed [1].

The beginning of intensive radial growth is associated with the growth of cloudy fibrillar shells on octahedral transparent 
crystals in diamonds of the IV variety according to Yu. L. Orlov. In diamonds of the $\mathrm{V}$ variety, the radial fibers begin in the center of the crystals and continue expanding to the periphery. Diamonds of these varieties are characterized by the presence of many cavities (scars), usually extending parallel to the fibers. They are usually associated with the course of hypothetical dissolution processes. However, the circulation of a dissolving viscous melt in a narrow cavity ending inside the crystal is practically impossible. These scars were formed due to a decrease in the rate of carbon diffusion, when its influx ceased to provide growth of fibers expanding to the periphery and empty gaps appeared between them. Scars in block crystals also seem to have a similar origin.

The late formation of varieties IV and V is often confirmed by the high content of the light carbon isotope accumulating in the residual melts and usually by a reduced value of the specific intensity of X-ray luminescence, indicating a large amount of impurities. Their high content, apparently, causes the coloration of most of the late crystals and their low jewelry quality. Radial growth is intensively manifested in viscous relatively silicic acid-rich magmas containing mainly dodecahedral diamonds. For example, crystals of the V variety are present in Arkhangelsk kimberlites containing an average of $41.16 \%$ silicic acid, but are absent in Yakut kimberlites with an average amount of $35.21 \%$ [3]. Due to the high content of silicic acid, the proportion of rounded dodecahedra in Arkhangelsk kimberlites is about 80\%, while they are almost absent in industrial Yakut pipes.

Rounded diamond crystals were formed under the influence of a reduction in the area of the resulting faces due to a decrease in the rate of carbon diffusion in fractionated magmas. That is, they are the result of anti-skeletal growth, and not dissolution, as is often assumed. This is usually confirmed by the larger size of rounded diamonds compared to planar diamonds in the same kimberlites and placers and the presence of rounded internal growth zones in some crystals. The reason for the hypothetical dissolution is usually not considered. Diamond dissolution processes could not exist in the cooled magmas, since carbon accumulation occurred in them during crystallization processes and the rate of its diffusion decreased, and this led to the antiskeletal growth of rounded crystals.

This origin of diamonds is confirmed by the evolution of the composition of mineral inclusions in them from peridotite paragenesis to eclogite, pyroxenite and then to kimberlite (carbonate-containing) [3] and an increase in the content of impurities accumulated in the residual melts of chemical components, including nitrogen and a light carbon isotope, by thousands of times from early diamonds to late ones. The impurities absorb X-ray luminescence. Therefore, in late diamonds, the specific intensity of X-ray luminescence decreases to almost zero, its value is an indicator of the time of formation of diamonds in the evolutionary sequence.

In the transitional upper part of the peridotite layer, the initially increased content of silicon and aluminum led to rhombododecahedral and cubic cutting of even early diamonds. Their immersion under the influence of an increased specific gravity in the peridotite lower parts caused their inclusion in the central parts of the octahedral crystals that appeared here later. The presence of such cubic and rhombododecahedral central regions does not contradict the early formation of octahedra in the middle and lower parts of the peridotite layer.

However, due to the presence of different sites and minerals in the magmatic ocean, its bottom fractionation was not accompanied by a complete separation of solid phases and melt. Part of the latter was buried among the kumulats. Therefore, after the completion of accretion, the bodies of melts were located at different depths in the cumulates underlying the magmatic ocean. During cooling, diamonds were also formed in them, which differed from the diamonds of the magmatic ocean by the presence of deeper inclusions. Sometimes the surfacing of such melts led to the introduction of ultra-high-baric diamonds into the magmatic ocean. Apparently, this explains the finds of diamonds with inclusions of ultra-high-baric minerals - ferripericlase, bridgmanite, stishovite. These minerals were formed at a depth of up to $600 \mathrm{~km}$ [8], while the magmatic ocean had a maximum depth of about $250 \mathrm{~km}$. The presence of carbonates in such inclusions, as well as ringwoodite with a water content of more than $1 \%$, confirms the crystallization of ultrahigh-baric diamonds in residual melts.

At the initial stages, the cooling of the bottom peridotite layer was slow, since it was overlain by the still hot upper layers. Therefore, a long (more than a billion years) crystallization led to the appearance of giant diamonds weighing up to many hundreds of carats, sometimes present in kimberlites. This origin is confirmed by a sharp predominance (in more than $99 \%$ [9, 10]) of octahedra among them and an increase in their size in the crystallization sequence - for smooth-sided octahedra it is on average 46 carats, for polycentric octahedra 50 carats, layered 72 carats, for occasionally occurring rhombododecahedra (3 out of 330) it is 151 carats. Due to the reduced content of crystallization centers in diamond-poor kimberlites, its crystals are more often larger on average than in rich ones.

The increase in the content of ultrabasic magma components in the magmatic ocean with the depth is the reason for the existence of a direct correlation of the diamond content of kimberlites with the concentration of magnesium, chromium, and cobalt in them, and the reverse - with the number of lithophilic components.

\section{The Nature of the Regularities of the Placement of Diamond-Bearing Kimberlites}

The most important regularity of the placement of diamond-bearing kimberlites was established in 1966 by $\mathrm{T}$. Clifford [11]. He drew attention to the fact that such kimberlites in Africa are found only in areas where the crystal foundation is more than 1.5 billion years old. Despite the small deviations from this rule, it is currently recognized 
by the overwhelming majority of researchers. But from the standpoint of traditional petrology, the nature of this rule is completely incomprehensible and its existence looks highly paradoxical. It would seem that kimberlites should be most widespread in the oceans, where there is a massive rise of mantle plumes and mafic magmatism is widespread. However, they are not there. Kimberlites carry out diamonds and, consequently, their melts were formed at a very great depth. These rocks are most often of Phanerozoic age. Therefore, it is not clear what the ancient age of the shallow parts of the Earth's crust has to do with their formation. For these reasons, the nature of the Clifford rule is almost not discussed and remains completely unclear. The obtained evidence of the hot accretion of the Earth and the existence of a global magmatic ocean on it fully explains the origin of the Clifford rule for the first time.

During hot accretion, kimberlite magmas arose from residual melts of its bottom peridotite layer. As a result of the formation of ancient cratons, kimberlite magmas were formed only under them and were introduced mainly into them by the crystallization of the magmatic ocean. Therefore, the existence of the Clifford rule is due to the common formation of cratons and kimberlite magmas by crystallization of the global magmatic ocean. In the case of rejuvenation of the crystalline basement by later processes, the peridotite layer, the parent for kimberlites, could move to a less deep level, which prevented the processes of diamond formation in it. During the formation of oceanic regions, the lithosphere of the ancient platforms was pushed apart by rising mantle plumes. This is the reason for the absence of kimberlites in these and collision areas.

The all-earth distribution of the magmatic ocean caused the presence of kimberlites on all the studied ancient platforms. Judging by the high content of meltophilic rare earths (up to a thousand chondrite norms), the volume of kimberlite residual melts was less than a thousandth of the peridotite layer. This explains the very small volume of kimberlite bodies (tenths-hundredths of a cubic kilometer). The formation of kimberlite fields on the Earth's surface allows us to assume an uneven distribution of kimberlite melts at the base of the lithosphere.

Often, the linear placement of kimberlite fields indicates a large role in the rise of kimberlite magmas of tectonic squeezing along the zones of stretching that arose in the lithosphere. The formation of such zones as a result of global plate-tectonic processes is probably the reason for the formation of kimberlites in the regions mainly at certain age epochs. Most often, the connection of kimberlites with submeridional tectonic faults (Figure 3) is due to the existence of a western continental drift caused by a deviation to the west under the influence of the Coriolis force of surfaced plumes and magmas [3]. During the formation of rifts, the lower layer of the lithosphere of the ancient platforms, which was ancestral for kimberlites, was apparently pushed apart by the spreading substance of convective flows. This usually explains the absence of a connection between the placement of kimberlites and rifts [12].
Together with kimberlites, carbonatite-containing magmatic complexes are located on ancient platforms, many of their rocks are similar in composition to kimberlites. Therefore, diamond searches were carried out in the areas of their distribution. However, these rocks usually do not contain diamonds. This is due to the formation of their melts from a fractionated picrite layer, which is less deep than peridotite (Figure 1). Kimberlites are usually absent in the areas of distribution of carbonatitecontaining complexes. Therefore, carbonatites and kimberlites are sometimes called relatives-antagonists [13]. Usually, the absence of diamond-bearing kimberlites in the area of alkalineultramafic massifs is probably due to the filling of deep stretching zones by earlier alkaline-ultramafic magmas, along which kimberlite magmas rise.

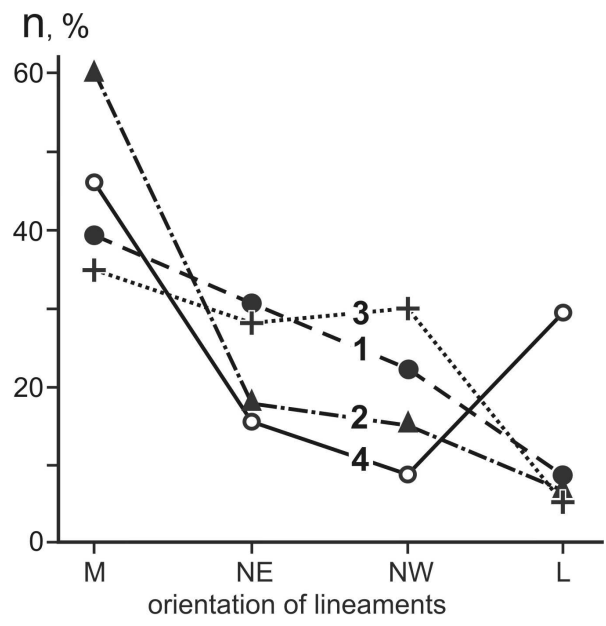

Figure 3. The number of kimberlite bodies (1), diamond-bearing fields (2), diamond-bearing differences of kimberlites (3), carbonatite bodies (4), controlled by lineaments of the submeridional $(M)$, north-eastern (NE), north-western $(\mathrm{NW})$ and sublatitudinal (L) orientation [12].

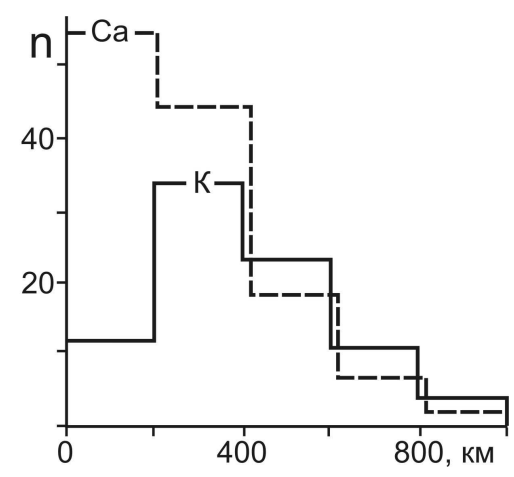

Figure 4. The dependence of the number (n) of carbonatite-containing complexes $(\mathrm{Ca})$ and kimberlite fields $(\mathrm{K})$ on the main platforms on the distance to their nearest edge [12].

As Figure 4 illustrates, the maximum number of carbonatite bodies is located at a distance of 0-200 km from the edges of ancient platforms, while kimberlites are most often $200-400 \mathrm{~km}$ away from them. This increased connection with the edges of the platforms is probably due to the +more intensive fragmentation of the marginal sections of the continental lithosphere under the influence of the 
movement of oceanic plates and the appearance of a larger number of magma channels here. Wedging on the margins of the deepest parts of the continental lithosphere, apparently, led to a smaller distribution of kimberlites at a distance of 0 $200 \mathrm{~km}$ from the edges of the platforms. The huge scale of deep fractionation over billions of years of a powerful (about $80 \mathrm{~km}$, Figure 1) picrite layer of the magmatic ocean led to a uniquely large accumulation of meltophilic elements - rare earth, rare, phosphorus, iron and others-in its residual carbonatite melts. This explains the unique high ore content of the carbonatite-containing complexes.

Along with kimberlites and carbonatites, traps are very widespread on all ancient platforms. It is usually assumed that their melts are separated from the peridotites of the upper mantle, which is melted by $15-20 \%$. However, the viscosity of such submerged rocks is approximately $10^{20}$ poise [14]. As calculations have shown, with such a high viscosity, smelting in the entire history of the Earth is able to float only for the first millimeters. In the only observable example of mass partial melting in migmatites, the anatectic vein material is not separated even at its content of $40 \%$. In the almost century-long history of using the partial melting hypothesis, not a single convincing geological proof of its validity has been given.

During the hot heterogeneous accretion of the Earth, trap magmas were formed as a result of decompression melting of surfaced large bodies of basic rocks that arose during the accretion of the mantle by filling impact craters on the bottom of the magmatic ocean with its bottom melts. Their tholeiitic composition is due to the small value of pressure that existed during the bottom fractionation of the early shallow magmatic ocean. The large size of the main bodies explains the rapid formation of huge volumes (millions of cubic kilometers) of traps. The earliest craters must have sometimes reached the iron core and captured its xenoliths. This is the reason for the presence of large bodies (up to tens of tons) of native iron in some traps. Its proximity in composition to iron meteorites [15], which are fragments of the iron cores of small planets, confirms the xenogenic origin of iron bodies in traps and the considered model of the formation and evolution of the Earth.

An important feature of the traps is the proximity of their isotopic age and the kimberlites present in the region (Figure 5). This seemingly surprising phenomenon is due to the impossibility of reaching the very deep main magmas of the Earth's surface with the existence of an inverse geothermal gradient in the mantle and uncured layers of the magmatic ocean. Judging by the beginning of the formation of oceanic regions at the end of the Proterozoic, a direct geothermal gradient in the mantle appeared at this time due to the heating of its very hot core. The formation and rise of kimberlite residual melts means almost complete solidification of the magmatic ocean and the possibility of reaching the Earth's surface of huge volumes of tholeiitic magmas. In the early Precambrian, the main magmas surfaced on ancient platforms from the basic layer of the magmatic ocean. They differ from traps in a higher content of alkalis and lithophilic components (up to $2.8 \% \mathrm{~K}_{2} \mathrm{O}$ ) due to their accumulation in the late magmatic ocean during fractionation processes.

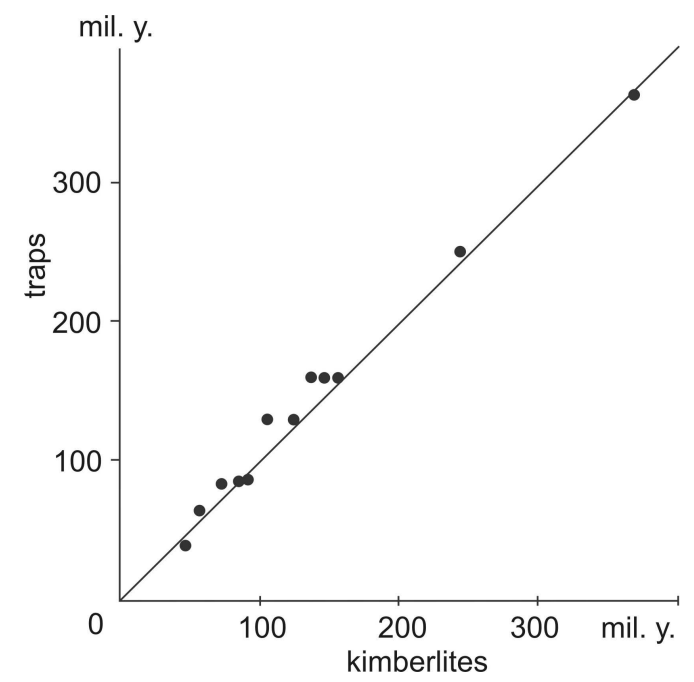

Figure 5. Correlation of the average isotopic ages of kimberlites and traps on the surface platforms. Built according to [16].

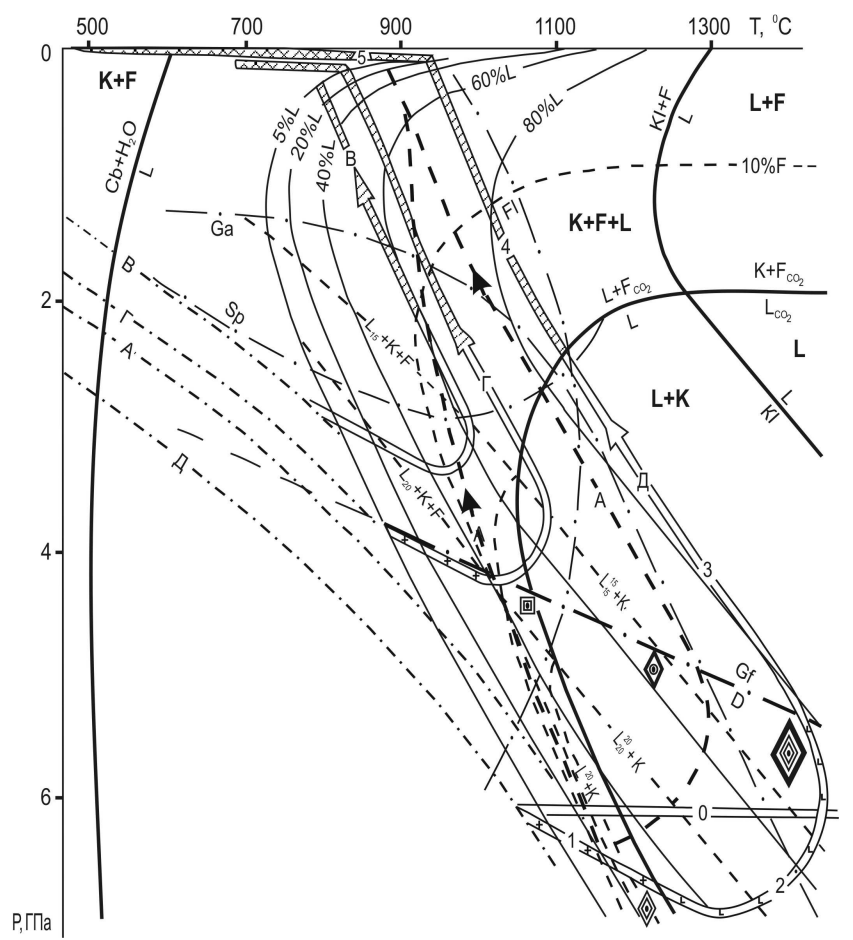

Figure 6. $P$-T diagram of the phase composition and evolution of kimberlite magmas (lines with arrows $\mathrm{A}-\mathrm{G}$ ) with a content of $10 \% \mathrm{H}_{2} \mathrm{O}$ and $10 \% \mathrm{CO}_{2}$. $C b$ - carbonate, D - diamond, Ga - garnet, Gf-graphite, Sp - spinel. F fluid, $K$ - the solid phases of kimberlite, $L_{20}{ }^{20}$ is the melt and the content of $\mathrm{H}_{2} \mathrm{O}$ (lower index) and $\mathrm{CO}_{2}$ (upper) in it. On the lines of evolution: 0 formation of the mantle; 1 and 2 - stages of intensive friction and decompression-friction melting, respectively; 3,4 and 5 -stages of decompression melting, decompression solidification and explosive disintegration, respectively. $A-G$ - lines of geothermal gradients. Crystal drawings - morphology of emerging diamonds.

The solution of genetic problems associated with the processes that occurred in magmas requires the development of quantitative models of magmas. The absence of such models led to the consideration of magmatic processes on the 
basis of speculative and therefore often erroneous assumptions. Figure 6 shows a quantitative model of the phase composition and evolution of kimberlite magmas with the most common content of $\mathrm{H}_{2} \mathrm{O}$ and $\mathrm{CO}_{2}$ in them by $10 \%$ calculated on the basis of published experimental and thermodynamic data [14]. It revealed the existence of unknown or little-known phenomena in these magmas. In the deepest field of melt + solid phases, there is no fluid phase in kimberlite magmas due to its complete dissolution in the melt. This contradicts the ideas about the origin of these magmas as a result of the hypothetical introduction of volatile and lithophilic components into the focus of magma formation. The rise in conditions of this field led to the melting processes of the contained solid phases, which explains the often rounded shape of the grains of early minerals in kimberlites.

At the shallow stages of ascent, a fluid phase appeared as a result of decompression boiling of the melt. Volatiles release caused decompression solidification of the upper parts of magmatic columns, which illustrates the intersection of the magma ascent lines of the melt isoconcentrate with decreasing values. During further ascent, an explosion occurred under the influence of the high pressure of the fluid phase preserved by solidification. This explains most often the formation of explosion pipes by kimberlite magmas, the high content of explosive breccias in them, and usually the absence of kimberlite lavas on the Earth's surface.

For explosions of kimberlite magmas, phreatomagmatic [17] or fluidomagmatic [18] origin is usually assumed. However, the first hypothesis is contradicted by numerous cases of magma basalts flowing into water without explosions. Due to their high fracturing, magmatic gases usually easily move over long distances through the host rocks with the formation of hydrothermal mineralization. For the explosions of kimberlite magmas, it is necessary to delay the expansion of magmatic gases for their very high pressure to occur. Decompression solidification of the upper parts of the rising magma columns creates this high pressure. It was equal to that at the deeper stages of magma ascent and was many times less than necessary for the formation of a diamond. This contradicts the sometimes assumed formation of diamonds as a result of an explosion.

Due to the large volume of the exploding substance, the strength of the decompression-hardened kimberlite magmas was thousands of times greater than atomic explosions [3]. This explains the crushing of powerful overlapping strata by them and the formation of extended pipes. In artificial explosions, the explosive is usually placed compactly. This leads to the appearance of wide craters during surface explosions, or cavities isolated from the surface at a very deep position of the explosive. The differences between kimberlite explosions and artificial ones led to the ideas about the absence of explosions during the formation of kimberlite pipes and about their occurrence as a result of the rise of fluidisites, which were a mixture of fluid with rock fragments and crystals. However, these concepts do not take into account that during the formation of the pipes, not a compact deep charge exploded, but an extended solidified column, which led to the appearance of large upwardexpanding cavities, to which kimberlite diatremes belong. The preservation of craters surrounded by kimberlite tuffs in some pipes quite definitely indicates the release of fragmented material outside the pipes characteristic of explosions.

Due to the approximately 5 times greater solubility of water in the melt compared to carbon dioxide, magmas rich in it decompressed solidified and exploded at a much lower depth than those rich in carbon dioxide. If kimberlite pipes have an average length of about a kilometer, then the diatremes that occurred during the explosion of carbon dioxide-poor acid magmas have a depth of usually tens of meters. The water content in kimberlite magmas is very difficult to reconstruct due to the widespread manifestation of postmagmatic serpentinization processes. Judging by the presence of less than a percent of carbon dioxide in some kimberlites, water was the main volatile component in some of them. This leads to an important conclusion that the carbon dioxide-poor and water-rich kimberlite magmas decompressed solidified and exploded almost on the Earth's surface. In this case, the predominant part of the kimberlite columns turned into tuffs, scattered over long distances and did not form significant diatremes made of detrital material.

A striking example is the pipes of the Bakwanga region in Africa, which are characterized by the presence of a saucershaped crater about a hundred meters deep on a narrow supply channel [13]. Diamond-bearing tuffizites and placers are located in the vicinity. Another example is the Karnian horizon of diamond-bearing tuffizites in the estuary part of the Lena River. Its length is about $500 \mathrm{~km}$ with a capacity of less than $0.5 \mathrm{~m}$ [19]. Rich placers of diamonds are widely distributed here. Despite extensive research, it has not yet been possible to find the root sources of alluvial diamonds. From the shallow depth of the explosions of water-rich magmas, it follows that the root sources had an insignificant size and by now could have been almost destroyed by erosion. Due to the richness of silicic acid in carbon dioxidepoor magmas, the proportion of octahedra in their diamonds was small and dodecahedroids prevailed. Therefore, a large proportion of them in placers and in Carnian tuffizites confirms the supposed origin of these rocks by the explosion of water-rich magmas.

Placers with large dodecaeroids of jewelry diamonds are widely distributed in South Africa. The large size of dodecahedroids in them is due to their origin in silicic acidrich magmas at the earliest stages of fractionation and, therefore, an increased duration of crystallization. A large number of thousand-ton samples were taken from kimberlite pipes to detect their root sources. But they could not be found [20]. It is obvious that these sources are completely destroyed or have an insignificant size. Such sources were found in the Vishersky Urals [21]. There are placers with large dodecahedroids of diamonds. Near the placers, maars, 
stockwork and secant bodies of tuffizites were found. They are usually wedged at a depth $50-100 \mathrm{~m}$, which confirms their formation as a result of shallow explosions of carbon dioxide-poor magmas.

Large diamonds could be formed only in the longfractionated deep parts of the magmatic ocean. Therefore, the presence of placers with large dodecahedroids of diamonds in many regions indicates the presence of areas with a high content of silicic acid and water in the bottom layer of the magmatic ocean. This is consistent with variations in the ratio of water to carbon dioxide in fluid inclusions in diamond from $0.05-0.2$ in the Yakut kimberlites to 1.0 in the kimberlites of Canada and Africa [22].

\section{Conclusion}

Thus, the obtained evidence of hot heterogeneous accretion of the Earth allows us to explain the genesis and the main features of the placement of kimberlites. According to these data, kimberlites and their diamonds were formed as a result of crystallization and fractionation of the bottom peridotite layer of the magmatic ocean, which arose under the influence of impact heat release during accretion. Early Precambrian protocratons were formed from its acidic layer. This explains the placement of diamond-bearing kimberlites only in them. The spread of the global magma ocean over the entire surface of the Earth caused the presence of kimberlites on all ancient platforms. The placement of kimberlites within the regions is determined by the features of Phanerozoic tectonic deformations that caused the appearance of extended magma channels that reached the base of the continental lithosphere.

\section{References}

[1] Shkodzinskiy V.S. Global petrology according to modern data on hot heterogeneous accretion of the Earth. Yakutsk: Publisher SVFU, 2018. 244 p.

[2] Ringwood A. E. Genesis of the Earth and the Moon. M.: Nauka, 1982. 294 p.

[3] Shkodzinskiy V.S. Genesis of lithosphere and and diamonds. Model of hot heterogenous accretion of the Earth. Saarbrücken: Palmarium academic publishing, 2015. 687 p.

[4] wikichi.ru/wiki/protoplanetary/disk.

[5] Mittchel R. H. Kimberlites, arangites, and related rocks. Plenum Press. New-York, 1995. 410 p.
[6] Sorohtin O. G. Evolution of the Earth, M.: MGU, 2002. 506 p.

[7] Lutkov V. C. Genesis of diamonds in alkaly basalts of the Tjan-Shan / Doklady of Tadgikistan. 2010. B. 53. N 5. P. 2136.

[8] Kaminsky F. V., Sablurovv S. M. Extraordinary diamond deposits / Nauka v Russii.. 2002. N 1. P. 5 - 12.

[9] Argunov K. P. Defektive diamonds and their diagnostics. Yakutsk: SB RAS, 2004. 216 p.

[10] Argunov K. P. Yakutia diamonds. Novosibirsk: SB RAS, 2006. $402 \mathrm{p}$.

[11] Clifford T. N. Tectono-metallogenic units and metallogenic provinces of Africa // Earth. Planet. Sci. Lett. 1966. N 1. P. 421-424.

[12] Frolov A. A, Lapin A. V., Tolstov A. V. Carbonatites and kimberlites (relations, minerals and prognosis). M.: NITAPriroda. 2005. 540 p.

[13] Belov C. V., Lapin A. V., Tolstov A. V., Frolov A. A. Mineralogy of platform magmatic rocks (trapes, carbonatites, kimberlites). Novosibirsk: Publisher SB RAS, 2008. 537 p.

[14] Shkodzinskiy $V . \quad S$. Phase evoluition of magmas and petrogenesis. M.: Nauka, 1985. 232 p.

[15] Shkodzinskiy V.S. Basic magmas carry aut fragments of the earth nucleus // Nauka i tehnika v Yakutii. 2020. N 1. P. 2-6.

[16] Arjasova D. V., Hasan Ja M.. Clifford rule and geodinamic of kimberlites // Geofisicgeskiy gurnal. 2013. B. 35. N 6. P. 101113.

[17] Lorenz V., Kurzlaukis S. Kimberlite pipes: growth models and resulting implications for diamond exploration // 8th International Kimberlite Conference. Long Abstract. Victoria: Canada, 2003.

[18] Skinner E. M., Marsh J. S. Kimberlite eruption processes // 8th International Kimberlite Conference. Long Abstract. Victoria, Canada, 2003.

[19] Grahanov S. A., Schatalov V. I. Schtyrov V. A. Diamond placers of Russia. Novosibirsk: GEO, 2007. 457 p.

[20] Podchasov V. M., Evseev M. N., Minorin V. E. Diamond placers of the World. M.: Geoinfrmark, 2005. 747 p.

[21] Rybalchenko A. Ja., Rybalcheno T. M., Silaev V. I. Teoretical basis of prediction and prospecting of native diamond tuffisites // Isvestia Komi nauchnogo zentra UrO RAN. 2005. B. 1 (5). P. 55-66.

[22] Zedgenizov D. F., Kagi Y., Shatsky N. P., Sobolev N. V. Carbonatitic melts in cuboid diamonds from Udachnaja kimberlite pype: evidence from vibrational spectroscopy / Mineralogical Magazine. 2004. V. 68 (1). P. 61-73. 